\title{
Extraction of Flavonoids from Sword Flower and Methodology of Its Preparations
}

\author{
Li Chongbi ${ }^{1, ~}{ }^{*}$ Xu Mingying ${ }^{1}$, Chen Ying ${ }^{2}$, Cai Ling ${ }^{2}$, Dong Shumei ${ }^{2}$ \\ ${ }^{1}$ Zhaoqing Medicine College, Zhaoqing City, China \\ ${ }^{2}$ Life College, Zhaoqing University, Zhaoqing City, China
}

Email address:

chongbili@163.com (Li Chongbi)

${ }^{*}$ Corresponding author

To cite this article:

Li Chongbi, Xu Mingying, Chen Ying, Cai Ling, Dong Shumei. Extraction of Flavonoids from Sword Flower and Methodology of Its Preparations. International Journal of Food Science and Biotechnology. Vol. 6, No. 1, 2021, pp. 8-20. doi: 10.11648/j.ijfsb.20210601.12

Received: January 6, 2021; Accepted: January 14, 2021; Published: January 22, 2021

\begin{abstract}
Qixing Jianhua (Hylocerei Undati Flos) is not only a specialty plant of Zhaoqing, but also has a lot of attention because it contains a variety of active ingredients. In order to explore the role of flavonoids in the seven-star sword-flower, by designing single factor test and L9 (Fourth power of 3) orthogonal test, the effects of different extraction time, ethanol concentration and particle size on the total flavonoids yield and process optimization were studied. After ultrasonic and $95 \%$ alcohol extraction, followed by ethyl acetate extraction, thin plate chromatography and other identification. Antioxidant ability analysis of the extract was carried out by salicylic acid method and antimicrobial test. And then the moisturizing anti-oxidation cream was prepared by using sword-flower alcohol extract. The results showed that the extraction rate was highest at $95 \%$ ethanol concentration, 1:60 of material to liquid ratio, 60 min extraction time, and 70 degrees Celsius extraction temperature, reaching $13.41 \mathrm{mg} / \mathrm{g}$. The antibacterial effect of the extract is obvious, and it has obvious scavenging effect of hydroxyl radicals. Therefore, this paper has important theoretical and practical significance for the further study and application of flavonoids in the future. It can be predicted that the flavonoids extracted from Qixing sword flower, a kind of traditional Chinese medicine in Zhaoqing, will be widely used in the fields of food, medicine and health in the future.
\end{abstract}

Keywords: Hylocerei Undati Flos, Extraction Process, Total Flavonoids, Preparation and Properties

\section{Introduction}

Jianhua is also known as the Overlord Flower, which is a perennial succulent climbing plant belong to genus of the cactus family (Hylocereus undatus Britt. Et Rose). It is native to the northern region from Central America to South America and widely cultivated or escaped. Seven Star Sword Flower (Hylocereus undatus Britt. Et. Rose) was named after growth on the cliffs of Qixingyan in Zhaoqing City, Guangdong Province. It is a unique species of Jianhua in Zhaoqing [1].

Flavonoid is secondary metabolites in plants and have a variety of physiological activities such as antibacterial, anti-inflammatory, antioxidant, and free radical elimination. They are particularly important in the treatment of cardiovascular diseases, such as strengthening, reducing blood pressure and blood lipids. Qixing Jianhua is mainly used as a product supply market. It is often used to make soup in Guangdong. It not only has a unique flavor, but also has an excellent health care. According to the study, the seven-star sword-flower is rich in vitamin C, flavonoids, polysaccharides and a large number of free amino acids.

Studies have shown that the extract of sword-flower has strong antioxidant activity [2-3]. However, no report was found on the extraction, identification and application of Flavonoids extract from the Seven Stars Swords. However, no report was also found on the extraction, identification and application of Flavonoid extract from the Seven Stars Swords. In this study, a series of single factor tests and orthogonal tests were carried out to optimize the quantitative analysis and extraction process of the flavonoid in Zhaoqing specialty, which was made of Qixing Jianhua. In order to find the best extraction method for practice, the extraction was identified, and the yield was analyzed. Considering the limitations of the application of flavonoid in sword-flower and the lack of standardized products, resulting in a low overall utilization 
rate, this study intends to use this extract as an antioxidant ointment preparation to improve its utilization rate. It provides a theoretical basis for the research and development of flavonoid extraction from Qixing Jianhua.

In recent years, with the gradual return of humans to the natural trend, the study of pure natural drug ingredients has become one of the focuses of medical attention and development around the world. It is believed that this research has important theoretical and practical significance for the development and utilization of local resources.

\section{Materials and Methods}

Seven Star Sword Dry Products (purchased from Zhaoqing Darunfa Supermarket); Rutin Standard Products (98\% biochemical reagents), Deionized Water, Anhydrous alcohol, Sodium Nitrite, Aluminum Nitrate, Sodium Hydroxide, Aluminum Chloride, Ethyl Acetate, Sodium Carboxymethyl Cellulose, Silica Gel G, Petroleum Ether (all analytical pure).

SHZ-D (III) circulating water multi-purpose vacuum pump (produced by Gongyi Yuhua Instrument Co., Ltd.); DJ-02 crusher of traditional Chinese medicine (produced by Shanghai Dianjiu Traditional Chinese Medicine Machinery Co., Ltd.); visible spectrophotometer (produced by Shanghai Branch Spectrometer Co., Ltd.); SH101-2 blast drying box (produced by Shanghai Hangzhou Instrument Co., Ltd.); Production; EQ-50E ultrasonic cleaner (produced by Kunshan Ultrasound Instrument Co., Ltd.); digital display constant temperature water bath pot HH-4 (produced by China Electrical Appliance Co., Ltd.); ZF-501 multifunctional ultraviolet projector (produced by Shanghai Gucun Electro-optical Instrument Co., Ltd.).

\subsection{Extraction of Inclution from Sword Flower}

The purchased dried products were washed and dried with deionized water and then dried in a blast drying box at 60 degrees Celsius. The dried products were crushed by a beater and sifted through 80,100, 150 and 200 meshes respectively. The dried products were sealed and preserved and marked for use. Accurately weigh $1.000 \mathrm{~g}$ of the dried pollen in $50 \mathrm{ml}$ plug cone flask, then accurately drop a certain concentration and volume of ethanol solution, and then soak for a period of time, and finally through the method of filtration to get the total flavonoid sample solution.

Therefore, the purchased dry products will be cleaned with clean water, spread flat on the iron plate, placed in the dryer low-temperature drying for 24 hours, after drying completely crushed with a pulverizer, through 200 mesh sieve, fine powder into a sealed bag and placed in a dry and cool place for reserve.

According to the related literature $[4,5]$, and considering the experimental conditions and equipment, the technological process of Flavonoid Extraction from Sword Flower was designed as follows:

$20 \mathrm{~g}$ sword dry powder was exacted by ultrasonic with 100 $\mathrm{ml} 95 \%$ ethanol for $1 \mathrm{~h}$, then cooled, filtrated, ultrasonic extraction with $100 \mathrm{ml} \mathrm{95 \%} \mathrm{ethanol} \mathrm{for} 1 \mathrm{~h}$ again, cooled. The extracted crude extracts were adjusted with $1 \%$ glacial acetic acid to $\mathrm{pH}$ between 3 to 4 . And the secondary extraction was got by rotary evaporation with ethyl acetate. Finally, the flavonoid extract was obtained after its drying.

\subsection{Identification of Sword Flower Extract}

\subsubsection{Strong Ammonia Reaction}

In fume hood, a piece of filter paper was taken and add 2-3 drops of extract at both ends of the filter paper (dried and dripped 1-2 times for concentration), one spot A as blank control point, the other spot B treated with ammonia for 2 min, it was observed directly [6].

\subsection{2. $\mathrm{AlCl}_{3}$ Reaction}

Flavonoid can react with aluminum salts to form yellow complexes and present fluorescence phenomena. Therefore, they can be used as an effective method to identify flavonoid. A clean filter paper was taken and dipped sample solution and rutin reference solution into both sides of the filter paper with a glass stick, and dry by air, then add a drop of $1 \% \mathrm{AlCl}_{3}$ ethanol solution in each of the two places, and then its color were observed under the ultraviolet projector $[7,8]$.

\subsubsection{Thin Plate Chromatography (TLC)}

Thin layer chromatography (TLC) is a solid-liquid adsorption chromatography (SLA) by using $0.5 \%$ sodium carboxymethyl cellulose (CMC) as binder to make silicage- $\mathrm{G}$ thin plate and activated. A clean capillary tube was used to point the sample solution and the reference solution on the same thin plate. The distance between the sample points must be more than $1 \mathrm{~cm}$. After drying, the sample was repeated 2-3 times at the same position. Then the sample was expanded with ethyl acetate-petroleum ether $(5: 1, \mathrm{~V} / \mathrm{V})$, and taken out when the front of the sample rose to two thirds of the thin plate. After drying, the thin plate was sprayed with a chromogenic agent ( $1 \% \mathrm{AlCl}_{3}$ ethanol solution), dried at 105 degrees Celsius for $10 \mathrm{~min}$, and then taken out. The phenomena were observed under UV projector [3, 7].

\subsection{Determination of Extract Content}

\subsubsection{Preparation of Rutin Standard Curve}

According to $\mathrm{Xu}$ Yingshu et al.'s report on the determination of total flavonoid in the extract of Herba Saxifragae by ultraviolet spectrophotometry [9], rutin was used as the standard for the determination of flavonoid. The concentration of rutin solution was $0.1 \mathrm{mg} / \mathrm{ml}$, and $0,2,4,6,8,10$, and $12 \mathrm{ml}$ were added into $50 \mathrm{ml}$ volumetric flask respectively. The reagent was added $1 \mathrm{ml}$ of $5 \%$ sodium nitrite solution, $10 \%$ aluminum nitrate solution, and $10 \mathrm{ml}$ of $4 \%$ sodium hydroxide solution successively, and after adding each reagent, shaking and blending were needed, and after standing still for $6 \mathrm{~min}$, the next reagent can be added. The constant volume of all the reagents were used in 30\% ethanol solution for $15 \mathrm{~min}$. Then the absorbance was measured at $510 \mathrm{~nm}$. Abscissa represented the concentration of rutin standard preparations, and ordinate was the absorbance value of the samples [10]. The standard curve of rutin was drawn by EXCEL 2010. 


\subsubsection{Determination and Calculation of Total Flavonoid}

The content determination of flavonoid in the extract of sword flower uses rutin as the standard substance. According to the above the method mentioned, absorbance data were obtained (see Table 1) and rutin standard curve equation was made. The results of rutin standard curve are as follows. $\mathrm{Y}=10.765 \mathrm{x}-0.0138, \mathrm{R} 2=0.9562$ (see figure 1 ).

Table 1. Rutin concentration and corresponding absorbance.

\begin{tabular}{lllllll}
\hline Rutin concentration $(\mathrm{mg} / \mathrm{ml})$ & 0 & 0.004 & 0.008 & 0.012 & 0.016 & 0.02 \\
corresponding absorbance & 0.00 & 0.03 & 0.07 & 0.11 & 0.14 & 0.18 \\
\hline
\end{tabular}

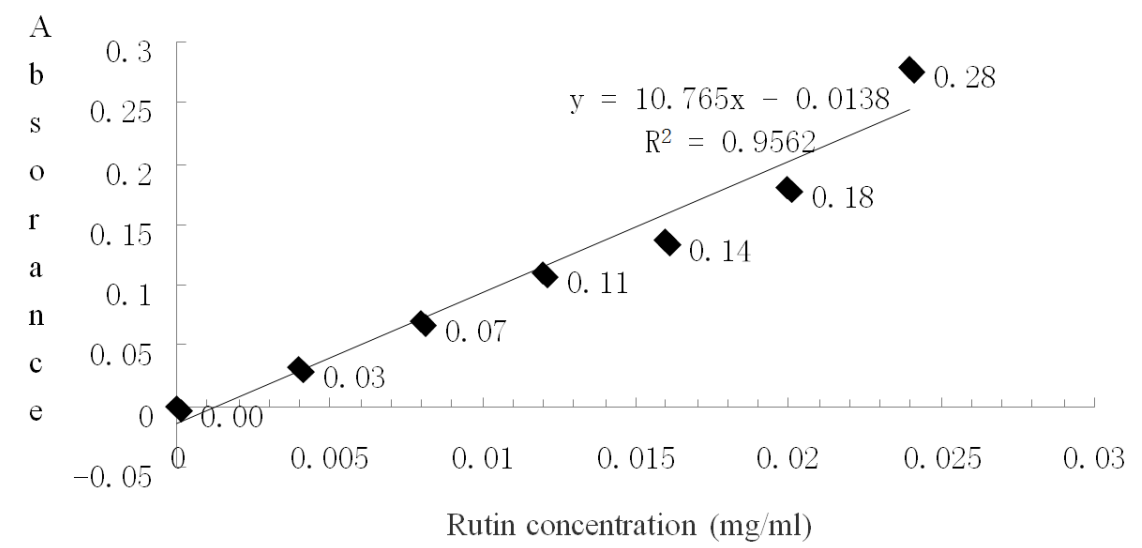

Figure 1. Rutin standard curve.

\subsubsection{Content Determination}

Diluting the extract to a certain concentration, the absorbance of the extract was measured according to the above method of determining the standard curve of Rutin, and the total flavonoid concentration of the extract was calculated according to the following formula [10].

Blank was $5 \% \mathrm{NaNO}_{2} \quad(1 \mathrm{ml}) \quad+10 \% \mathrm{Al}\left(\mathrm{NO}_{2}\right)_{3} \quad(1 \mathrm{ml})$ $+4 \% \mathrm{NaOH}(10 \mathrm{ml})$

Sample was the sample solution $(2 \mathrm{ml}) 5 \% \mathrm{NaNO}_{2}(1 \mathrm{ml})$ $+10 \% \mathrm{Al}\left(\mathrm{NO}_{2}\right) 3(1 \mathrm{ml})+4 \% \mathrm{NaOH}(10 \mathrm{ml})$

The absorbance value of the sample solution was determined by above method introduced. The calculation methods are as follows.

$$
\mathrm{W}(\mathrm{mg} / \mathrm{g})=\frac{C \cdot V_{1} \cdot V_{2}}{M \cdot V_{3}}
$$

In the formula, $\mathrm{W}$ is the total flavonoid amount $(\mathrm{mg} / \mathrm{g}), \mathrm{C}$ is the concentration of total flavonoids in the extract $(\mathrm{mg} / \mathrm{mL})$, $\mathrm{M}$ is quality of sword flower $(\mathrm{g}), \mathrm{V} 1$ is the volume of the liquid to be measured $(\mathrm{ml}), \mathrm{V} 2$ is the volume of total flavonoids extract $(\mathrm{ml}), \mathrm{V} 3$ is the volume of the extract $(\mathrm{ml})$

\subsubsection{Stability of Extracts}

The absorbance value of the sample solution prepared were examined every $10 \mathrm{~min}$ At $510 \mathrm{~nm}$ within $60 \mathrm{~min}$. Relative standard deviation (RSD)=standard deviation (SD) / arithmetic mean of calculation result $(\mathrm{x}) \times 100 \%$. The size of RSD was $2.813 \%$, that is, the sample liquid remained stable in $60 \min [8]$.

\subsubsection{Reproducibility of Extracts}

Six samples with the same quality were accurately weighed and the total flavone extracts were prepared under the same conditions. The average absorbance of the extracts was 0.836 and RSD was $0.891 \%$ by the procedure mentioned. It was shown that the experiment had good repeatability.

\subsubsection{Extraction Process}

(1) Ten samples, each $1.00 \mathrm{~g}$ was weighed accurately by an electronic analytical balance. After $30 \mathrm{ml} 95 \%$ ethanol solution was dripped, the samples were extracted in the rotary evaporator (RE-52AA Shanghai) at room temperature for 30 min. Then the obtained solution was filtered by a multi-purpose vacuum pump with circulating water, and 10 samples of clarified extracts were obtained. The total flavonoid yield of the extraction was determined according to the method mentioned above.

(2) Ten samples, each $1.00 \mathrm{~g}$ was also weighed. The extraction conditions were the same as those of the above. The total flavonoid were extracted by ultrasonic way shocking for $30 \mathrm{~min}$, then filtered and obtained the total flavonoid of Seven Stars Sword Flower. The total flavonoid yield of the extractions was determined according to the method above.

(3) The data obtained from the two groups of comparative tests were analyzed by independent test of $2 \mathrm{x}$ c list union table, in which $\mathrm{df}>2$, so no continuous correction was needed in calculating $\mathrm{X}$ square.

\subsubsection{Selection of Extraction Conditions}

Single factor test The purpose of this experiment was taken by using the extraction amount of total flavonoid, the samples were prepared in parallel with the methods of determination and calculation of total flavonoid content above. The effects of ethanol concentration, extraction times, sample particle size, extraction time, solid-liquid ratio and temperature on the total content of Seven Star Swordflower were investigated by 
single factor analysis of variance and least significant difference (LSD) method. The influence of flavonoid extraction and their optimal level orthogonal experiment.

According to the results of single factor experiment, four factors, ethanol concentration (A), solid-liquid ratio (B), extraction time (C), temperature (D), were selected to carry out orthogonal test of L9 (34). The test scheme is shown in Table 2, and the best extraction process is determined by range method.

Table 2. L9 (3 square 4) orthogonal test factor table.

\begin{tabular}{|c|c|c|c|c|}
\hline Horizontal factors & ethanol concentration $(\%)$ & solid-liquid ratio $(\mathrm{g} / \mathrm{ml})$ & extraction time (min) & Temperature $\left({ }^{\circ} \mathrm{C}\right)$ \\
\hline 1 & 80 & $1: 40$ & 45 & 60 \\
\hline 2 & 90 & $1: 50$ & 60 & 70 \\
\hline 3 & 95 & $1: 60$ & 75 & 80 \\
\hline
\end{tabular}

Verification of optimum process Based on the orthogonal test results, three extracts of total flavonoid were prepared by the optimum extraction process, and the content of total flavonoid in the extracts was determined by the method shown above.

The total flavonoid extracted were concentrated, sealed and stored in cold storage for use in next step.

Data processing The absorbance values of total flavonoid extracts were determined by three parallel experiments, and the total flavonoid yield was calculated by 3.3.1 method. The data were expressed and processed by EXCEL 2010 and SPSS 20.0 software [7].

Antioxidant capacity The concentration of extracted liquid was adjusted to $0.1 \mathrm{mg} / \mathrm{ml}$, and 5 concentration gradients were used to carry out antioxidant experiments. The operation of antioxidant test is carried out in Table 3.

Table 3. Antioxidant procedure of brass extract.

\begin{tabular}{llllll}
\hline Serial num & 1 & 2 & 3 & 4 & 5 \\
Sample vol (ml) & 4 & 5 & 6 & 7 & 8 \\
Flavoid content (mg) & 0.4 & 0.5 & 0.6 & 0.7 & 0.8 \\
\hline
\end{tabular}

\subsection{Preparation of THE Cream from Ethanol Extract of Sword Flower}

Sword flower samples were washed with deionized water and then dried in an air blast drying chamber at 60 degrees Celsius until their weight did not change. The raw materials for drying were taken out, crushed and sifted through 200 meshes to obtain the required sample powder. Sample powder was weighed and put into conical bottle. 95\% ethanol was added according to the ratio of material to liquid at 1:3, shaking well and bathing at 80 degrees Celsius for $30 \mathrm{~min}$ [5]. The supernatant was extracted and filtered, and the ethanol was evaporated by rotating evaporation mentioned above. The extract was concentrated, sealed and stored in cold storage for reservation.

\subsubsection{Preparation and Properties of Cream Base}

The cream was a semi-solid preparation for external use [11] in which extracts were dispersed or dissolved in an emulsion matrix. The cream should be free from decay and odor, water and oil stratification, gas expansion, discoloration and rough phenomena. The cream should have a certain consistency, be easy to coat and not melt. Therefore, the selected matrix should basically meet the following conditions: Firstly, it is uniform and delicate texture, lubrication and no harm to the human body with appropriate consistency, and easy to coat on the skin. Secondly, it has a stable nature, not affecting the main drug performance. Thirdly, it is not affecting the normal physiological function of human skin with excellent drug release performance. It is also easy to clean and will not pollute clothes.

Usually, the matrix of the cream consists of two types, namely, oil in water (W/O) and oil in water $(\mathrm{O} / \mathrm{W})$ type [12]. Studies have shown that the drug release performance of different matrix compositions was different [13-14]. Among them, $\mathrm{O} / \mathrm{W}$ matrix not only had better drug release performance, but also enhances the synergistic effect between different drugs, and improves the utilization of effective components of drugs. Moreover, the greasy feeling of $\mathrm{O} / \mathrm{W}$ matrix is weak and easy to remove. At the same time, because the outer phase of $0 / \mathrm{W}$ matrix is water, it is easier to smear. In this experiment, $\mathrm{O} / \mathrm{W}$ matrix was used to make the cream.

Table 4. Matrix prescription screening.

\begin{tabular}{llllll}
\hline \multirow{2}{*}{ Matrix (g) } & \multicolumn{4}{c}{ Prescription number } \\
\cline { 3 - 6 } & Sweet almond oil & $\mathbf{1}$ & $\mathbf{2}$ & $\mathbf{3}$ & $\mathbf{4}$ \\
\hline \multirow{3}{*}{ Oil } & Vaseline & 15 & 10 & 6 & 4 \\
phase & 1-octadecanol & 10 & 5 & 3 & 2 \\
& Emulsifiers: Glycerol Monostearate & 3.8 & 3.8 & 3.8 & 3.8 \\
& Glycerol & 8 & 8 & 8 & 8 \\
\multirow{3}{*}{ Water } & Glycerin & 2 & 2 & 2 & 2 \\
phase & Preservative: potassium sorbate & 0.5 & 0.5 & 0.5 & 0.5 \\
& Emulsifier: sodium dodecyl Sulfate & 1.2 & 1.2 & 1.2 & 1.2 \\
\multirow{2}{*}{ Total } & Deionized water & 39.5 & 59.5 & 69.5 & 74.5 \\
\hline
\end{tabular}

Notes* Oil sweet almond oil 151064, Vaseline 10532, 1- eighteen alcohol 201064, Emulsifier, glycerin monostearate 3.8, Aqueous Glycerin 8888.

It was determined that the oil phase matrix is vaseline, sweet almond oil, 1-octadecanol, and the water phase matrix is glycerol, glycerin and deionized water by consulting a large number of related literatures. Because the oil and water phases are not compatible, the appropriate emulsifier should be selected according to the Hydrophile-Lipophile Balance (HLB) of the matrix in order to reduce the surface tension of the oil-water interface. The HLB value of the emulsifier used as $\mathrm{O} / \mathrm{W}$ matrix should be between 8 and 16 according to the requirement, so HLB has been chosen in the experiment. Glycerol monostearate with a value of 3.8 and sodium dodecyl sulfate with a HLB value of 40 are used as emulsifiers in proportion. The amount and proportion of oil and water phases were screened through experiments. The results of matrix 
screening are shown in Table 4.

\subsubsection{Matrix Emulsification}

Firstly, the substances belonging to the water phase were put into the beaker and heated to 80 degrees Celsius to melt all of them into transparent state. After stirring uniformly, the temperature was kept at 80 degrees Celsius, the water phase was slowly poured into the oil phase at 80 degrees Celsius when the oil phase was melted into transparent liquid. Then it was emulsifying for 10-15 min at $500 \mathrm{~g}$ in a collector-heated magnetic stirrer, the cream gradually would be solidified at room temperature [15-17]. At this time, the cream would be moderately thick, milky white, glossy, delicate, soft and easy to spread.

\subsubsection{Physical and Chemical Properties}

(1) It should be uniform and delicate, moderate viscosity, gloss, easy to spread and wash in the appearance of the matrix, $[17,18]$.

(2) The matrix would be diluted with deionized water in proportion to $1: 5$, and the $\mathrm{pH}$ of $\mathrm{O} / \mathrm{W}$ matrix is not more than 8.3 meeting the requirements of 4.0-8.5 after stirring according to pharmacopoeia.

(3) $3 \mathrm{~g}$ samples of different prescriptions were weighed and placed in centrifugal tubes of $10 \mathrm{ml}$ for $30 \mathrm{~min}$ at $2500 \mathrm{~g}$, the samples were taken out and smeared on slide. No phenomena of demulsification, roughening and oil-water layer should be observed [19].

(4) $3 \mathrm{~g}$ samples of different prescriptions were weighed each and placed in sealed containers and kept for $24 \mathrm{~h}$ in a constant temperature box at 40 degrees Celsius at -20 degrees Celsiusa in refrigerator. Then the samples were taken out and placed at the restored room temperature. The consistency, uniformity and color of the samples would be checked after uniformly smearing on the slide to see whether the emulsification and oil-water stratification phenomenon were broken or not [17-19].

Determination of the cream moisture retention

In this study, it was examined that a glass plate with medical breathable tape was substituted for human skin in vitro not considering about the absorption function of the skin in order to make the experiment more realistic. The size of the glass plate was $2.5 \mathrm{~cm} * 4 \mathrm{~cm}$, and the sample was taken $0.1 \mathrm{~g}$ (accurate to $0.001 \mathrm{~g}$ ), which was equivalent to $10 \mathrm{mg} / \mathrm{cm}^{2}$. After evenly applying the sample on the glass plate with medical breathable tape, it was immediately put into a dryer with relative humidity (RH\%) of $44 \pm 5 \%$ and temperature of 20 degree Celsius. It was weighed after $4 \mathrm{~h}$ [19]. The moisturizing rate is calculated according to the following formula.

$$
\text { Moisturizing rate }=\frac{M_{t 0}}{M_{t 4}} \times 100 \%
$$

Notes* $M_{t 4}$, water weight after placing $4 \mathrm{~h} . \mathrm{M}_{\mathrm{t} 0}$, water weight before placing.

The experiment was divided into three groups, blank control group, sample group and background control group. According to the following methods, reagents were added in turn, and then bathed in a constant temperature water bath at 37 degrees
Celsius. After $30 \mathrm{~min}$, those were taken out for cooling. The OD value of aborbance at wavelength of $510 \mathrm{~nm}$ was determined by spectrophotometer. The scavenging rate of hydroxyl radicals was calculated according to the formula 1 . The antioxidant experiment steps of rutin are the same as above.

$$
\mathrm{OH}-=[1-(\mathrm{Ax}-\mathrm{Axo}) / \mathrm{Ao}] \times 100 \%
$$

$\mathrm{Ao}=1 \mathrm{ml} 9 \mathrm{mmol} / \mathrm{L}$ ferrous sulfate solution $+1 \mathrm{ml} 9 \mathrm{mmol} / \mathrm{L}$ salicylic acid ethanol solution $+1 \mathrm{ml}$ hydrogen peroxide + distilled water

$\mathrm{Ax}=1 \mathrm{ml} 9 \mathrm{mmol} / \mathrm{L}$ ferrous sulfate solution $+1 \mathrm{ml} 9 \mathrm{mmol} / \mathrm{L}$ salicylic acid ethanol solution + sample solution $+1 \mathrm{ml}$ $8.8 \mathrm{mmol} / \mathrm{L}$ hydrogen peroxide + distilled water

$\mathrm{Axo}=1 \mathrm{ml} 9 \mathrm{mmol} / \mathrm{L}$ ferrous sulfate solution $+1 \mathrm{ml} 9 \mathrm{mmol} / \mathrm{L}$ salicylic acid ethanol solution + sample solution + distilled water

\section{Comments}

$0.2502 \mathrm{~g}$ seven water ferrous sulfate $+100 \mathrm{ml}$ distilled water $0.1242 \mathrm{~g}+100 \mathrm{ml}$ salicylic acid absolute ethanol 88.9 um $70 \%$ hydrogen peroxide $+100 \mathrm{ml}$ distilled water

Ao - blank control, Ax - Sample, Axo background comparison

\subsection{Comparison of Hydroxyl Radical Scavenging Rate of Sword Flower Extract}

The sample solutions of 1, 2, 3, 4 and $5 \mathrm{mg} / \mathrm{ml}$ of sword flower extract were prepared with anhydrous alcohol 11-12]. Salicylic acid capture method is that $\mathrm{OH}$ was produced by fenton reaction and 2,3-dihydroxybenzoic acid was being produced by oxidation of salicylic acid with $\mathrm{OH}$. The maximum absorption wavelength of the substance is at $510 \mathrm{~nm}$. The scavenging rate of $\mathrm{OH}$ is determined by measuring the products captured by salicylic acid. In the reaction system, $1 \mathrm{~mL}$ of sample solution with concentration of 1, 2, 3, 4 and $5 \mathrm{mg} / \mathrm{ml}$ was selected and placed in different test tubes. $9 \mathrm{mmol} / \mathrm{L} \mathrm{FeSO}_{4} 1 \mathrm{~mL}, 9$ $\mathrm{mmol} / \mathrm{L}$ salicylic acid-ethanol solution $1 \mathrm{~mL}$ were added in the same tubes sequentially. Finally, $8.8 \mathrm{mmol} / \mathrm{L} \mathrm{H}_{2} \mathrm{O}_{2} 1 \mathrm{~mL}$ were added to start the reaction, and the reaction was maintained at $37 \mathrm{C}$ for $30 \mathrm{~min}$.

Using deionized water as reference, the absorbance of each concentration sample was measured at $510 \mathrm{~nm}$ wavelength. Considering the absorbance value of the sample and the system itself, the background absorbance values of the samples were 9 $\mathrm{mmol} / \mathrm{L} \mathrm{FeSO}_{4} 1 \mathrm{~mL}, 9 \mathrm{mmol} / \mathrm{L}$ salicylic acid-ethanol solution $1 \mathrm{~mL}, 1 \mathrm{~mL}$ and $1 \mathrm{~mL}$ deionized water of different concentration. The blank control was $9 \mathrm{mmol} / \mathrm{L} \mathrm{FeSO}_{4} 1 \mathrm{~mL}, 9 \mathrm{mmol} / \mathrm{L}$ salicylic acid-ethanol solution $1 \mathrm{~mL}, 8.8 \mathrm{mmol} / \mathrm{L} \mathrm{H}_{2} \mathrm{O}_{2} 1 \mathrm{~mL}$ and $1 \mathrm{~mL}$ anhydrous ethanol. The absorption value of the liquid were determined as references [11, 12]. Calculation - $\mathrm{OH}$ clearance rate was the formula as follows.

- $\mathrm{OH}$ clearance rate $=(\mathrm{A} 0-\mathrm{AX} 1+\mathrm{AX} 2) / \mathrm{A} 0 \times 100 \%$

A0 - blank contrast solution absorbance; AX1 - absorbance after adding sample solution; AX2 - background absorbance of sample solution without $\mathrm{H}_{2} \mathrm{O}_{2}$. 


\subsection{Bacteriostatic Ability Determination}

Bacteria incubation medium 3 liquid media can be prepared including beef extract $0.6 \mathrm{~g}$, peptone $2.0 \mathrm{~g}$, sodium chloride $1.0 \mathrm{~g}$ and Distilled water $200 \mathrm{ml}$. The formula of solid medium is beef extract $1.2 \mathrm{~g}$, bacteriological peptone $4.0 \mathrm{~g}$, sodium chloride $2.0 \mathrm{~g}$, agar $4.0 \mathrm{~g}$, distilled water $400 \mathrm{ml}$. The $\mathrm{pH}$ value is adjusted by sodium hydroxide from 7.2 to 7.6.

The strains for bacteriostasis test were Escherichia coli, Staphylococcus aureus and Bacillus subtilis provided by our laboratory. The strains were shaken at 37 centigrade for two days to activate the strains.

adjustment of different concentration gradients and preparation of filter paper

Five concentration gradients of the extracts were prepared by dilution with $95 \%$ ethanol as the solvent on the aseptic operating table. They were $10 \mathrm{mg} / \mathrm{ml}, 5 \mathrm{mg} / \mathrm{ml}, 2.5 \mathrm{mg} / \mathrm{ml}$, $1.25 \mathrm{mg} / \mathrm{ml}$ and $0.625 \mathrm{mg} / \mathrm{ml}$, respectively.

A puncher of $6 \mathrm{~mm}$ diameter was used to punch uniform and sufficient circular filter paper with $6 \mathrm{~mm}$ diameter on the qualitative filter paper. After high temperature disinfection, a certain number of filter paper discs were put into different concentration gradient extracts for 24 hours [13].

\subsection{Bacteriostasis Operation}

After the bacteria were completely activated, they were coated on the aseptic table and placed in filter paper. Bacillus subtilis, Staphylococcus aureus and Escherichia coli 100ul suspensions were put into the plate and coated with sterile rod to make the bacterial liquid evenly distributed. And then the filter paper soaked in different concentrations of extract solution with tweezers sterilized at high temperature were clamped out and placed on the corresponding label concentration medium., A filter paper soaked in absolute ethanol as a control and the other three filter papers soaked in the extraction were in each medium. The Petri dish with filter paper was inverted and cultured at $37 \mathrm{C}$ incubator for 12 hours, and the size of bacteriostatic circle of filter paper was determined, and the data were recorded.

The antibacterial activity of rutin was the same as above.

\section{Results}

\subsection{Comparison Between Normal Extraction and Ultrasonic Method}

In order to more reasonably and accurately evaluate the effect of extraction on the extraction of total flavonoids from Hepta star Sword flower, the author compared the steam distillation with ultrasonic extraction, and then the experimental data were examined by X2 (see table 5). By calculating the average yields of the two methods. It could be seen that the yields was $6.611 \mathrm{mg} / \mathrm{g}$ by normal extraction method, and $7.261 \mathrm{mg} / \mathrm{g}$ by ultrasonic method, which indicated that the ultrasonic had little effect on the yield (Figure 2). Therefore, the normal extraction could be regarded as an energy-saving, and it is simple, high extraction rate, effective and feasible method for the extraction of total flavonoids from Sword Flower.

Table 5. Results of X square test for two extraction methods.

\begin{tabular}{llll}
\hline & X2 & df & $\begin{array}{l}\text { progressive } \\
\text { Sig. (bilateral) }\end{array}$ \\
\hline Pearson X2 & $0.07435 \mathrm{a}$ & 9 & 1.00000 \\
Likelihood ratio & 0.07435 & 9 & 1.00000 \\
Linear and linear combination & 0.00017 & 1 & 0.98966 \\
effective cases N & 139 & & \\
\hline
\end{tabular}

\subsubsection{Single Factor Test on Ethanol Concentration}

Results showed that the total flavonoids content of Swordflower increased first and then decreased, reaching a peak value of $7.192 \mathrm{mg} / \mathrm{g}$ when the concentration was $90 \%$ with the increase of ethanol concentration after preliminary experiments, at the same ratio of material to liquid as 1:30, the ethanol concentration was $50 \%, 60 \%, 70 \%, 80 \%, 90 \%, 95 \%$ and $100 \%$ respectively (see Figure 2 and table 6 ). The experimental data were analyzed by one factor variance, and the result showed that the effect of ethanol concentration was very significant $(\mathrm{P}<0.01)$. In order to further compare the differences among different levels, a multiple comparative analysis table (Table 7) was established. The results showed that the extraction effect of $90 \%$ ethanol was not significantly different from that of $95 \%$, but the difference was very significant with other levels. Based on the above analysis, the optimum ethanol concentration for extracting total flavonoids from sword flower was determined to be between 90-95 percent..

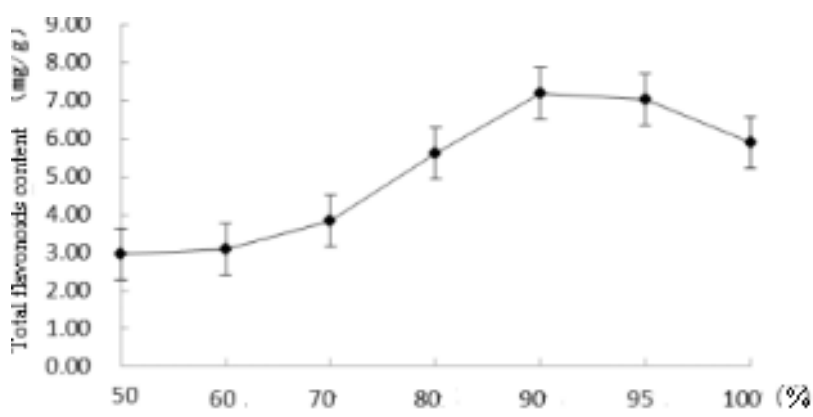

Figure 2. Different concentration of Ethanol Extraction of Flavonoids.

Table 6. Variant analysis of the effect on extraction of total flavonoids from Swordflower with ethanol.

\begin{tabular}{llllll}
\hline Source of difference & SS & df & MS & F & P-value \\
\hline Inter group & 57.775 & 6 & 9.629 & $2304.156^{* *}$ & $<0.001$ \\
group & 0.059 & 14 & 0.004 & & \\
total & 57.833 & 20 & & & \\
\hline
\end{tabular}

Note: * The effect of the extraction of total flavonoids affecting factors is very significant $(\mathrm{P}<0.01)$. 
Table 7. Effects of the extraction of total flavones from Swordflower with different ethanol concentration.

\begin{tabular}{llll}
\hline \multirow{2}{*}{ Ethanol Concentration (\%) } & Average total flavonoids content $(\mathbf{m g} / \mathbf{g})$ & Significant differences & \\
\cline { 3 - 4 } & & $\mathbf{a}=\mathbf{0 . 0 5}$ & $\mathrm{a}=\mathbf{0 . 0 1}$ \\
\hline $90 \%$ & 7.192 & $\mathrm{a}$ & $\mathrm{A}$ \\
$95 \%$ & 7.011 & $\mathrm{a}$ & $\mathrm{A}$ \\
$100 \%$ & 5.882 & $\mathrm{~b}$ & $\mathrm{~B}$ \\
$80 \%$ & 5.594 & $\mathrm{~b}$ & $\mathrm{~B}$ \\
$70 \%$ & 3.815 & $\mathrm{c}$ & $\mathrm{C}$ \\
$60 \%$ & 3.072 & $\mathrm{~d}$ & $\mathrm{D}$ \\
$50 \%$ & 2.951 & $\mathrm{~d}$ & $\mathrm{D}$ \\
\hline
\end{tabular}

Note* There are significant differences between levels that do not contain the same letter, and there is no significant difference where there is an identical letter.

\subsubsection{Single Factor Test of Extraction Times}

Four gradients of different extraction times were designed when the extraction conditions were as normal room temperature, $90 \%$ ethanol, solid-liquid ratio of $1: 30$ and extraction time of 30 minutes. And it started at one time then increased to four times with one gradient. The results showed in Figure 3. The total flavonoid extraction amount of Heptastar Sword flower increased with the increase of extraction times, but no significant. In order to further explore its effect on extracting total flavonoids from Heptastar sword flower and the difference among different levels, the data were analyzed by variance analysis (Table 8) and multiple comparisons (Table 9). $\mathrm{F}=847.5063>$ Fcrit in Table 7, and $\mathrm{P}<$ 0.01 , showed that the effect of extraction times was very significant; through multiple comparative analysis in Table 8, only the difference between three and four extraction times did not reach very significant level, and the difference between other levels reached very significant level.

Based on the above results, in order to operate conveniently and save experimental reagents, the following experiments still use extraction times as one time to extract total flavonoids. But if a large amount of total flavonoids is extracted, it is recommended to extract 3-4 times.

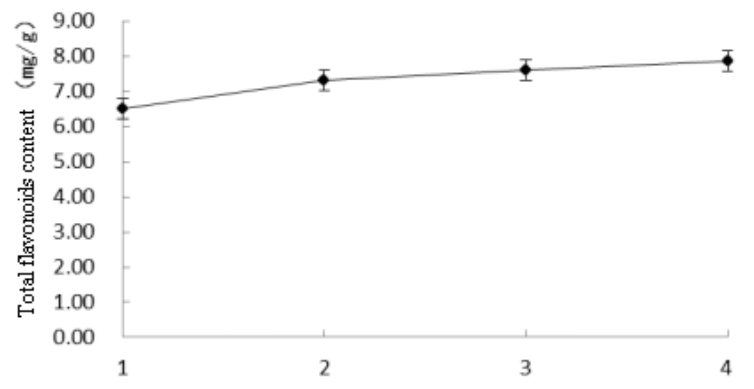

Figure 3. Different extraction times.

Table 8. Variance analysis of the effect on extraction frequency of total flavonoids from Swordflower.

\begin{tabular}{llllll}
\hline Source of difference & SS & df & MS & F & P-value \\
\hline Inter group & 3.044 & 3 & 1.015 & $847.506^{* *}$ & $<0.001$ \\
Group & 0.010 & 8 & 0.001 & & \\
Total & 3.054 & 11 & & & \\
\hline
\end{tabular}

Table 9. Multiple comparison of LSD effects on total flavonoids extraction frequency.

\begin{tabular}{llll}
\hline Extraction & $\begin{array}{l}\text { Average total flavonoids } \\
\text { frequency }\end{array}$ & \multicolumn{2}{c}{ Significant differences } \\
\cline { 3 - 4 } & content $(\mathbf{m g} / \mathbf{g})$ & $\mathbf{a}=\mathbf{0 . 0 5}$ & $\mathbf{a}=\mathbf{0 . 0 1}$ \\
\hline 4 & 7.848 & $\mathrm{a}$ & $\mathrm{A}$ \\
3 & 7.614 & $\mathrm{~b}$ & $\mathrm{~A}$ \\
2 & 7.314 & $\mathrm{c}$ & $\mathrm{B}$ \\
1 & 6.514 & $\mathrm{~d}$ & $\mathrm{C}$ \\
\hline
\end{tabular}

\subsubsection{Single Factor Test of Extraction Time}

The total flavonoid yield of Hepta star Sword flower increased greatly before 45 minutes, but slowed down after 45 minutes when the extraction time were $15,30,45,60,75$ and $90 \mathrm{~min}$, respectively under the conditions of $90 \%$ ethanol concentration, ratio of material to liquid 1:30 and normal temperature. The results of single factor test at different time were as follows (Figures 4, 5). In order to improve the extraction efficiency of total flavonoids under the condition of high extraction quantity, it could be seen from the broken line chart and the analysis of variance table table (Table 10) and multiple comparison table (Table 11). It was suggested that the extraction time should be about 45-60 minutes.

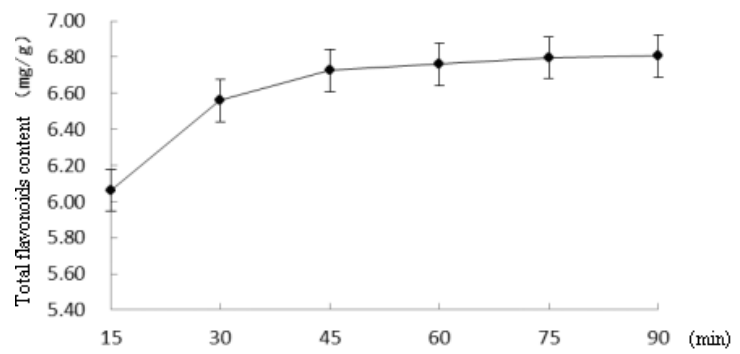

Figure 4. Ectraction time single factor composition.

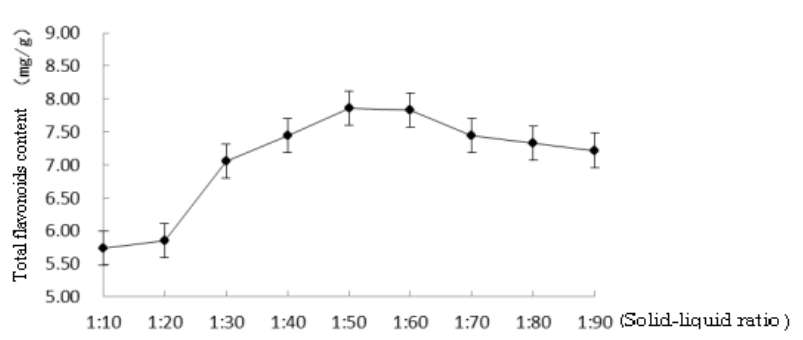

Figure 5. Effect of material-liquid ratio on extraction of total flavonoids from sword flower. 
Table 10. Analysis of variance of effect on extraction time of total flavonoids from Swordflower.

\begin{tabular}{lllllll}
\hline Source of difference & SS & df & MS & F & P-value & F crit \\
\hline Inter group & 1.232 & 5 & 0.246 & $476.033^{* *}$ & $<0.001$ & 3.106 \\
Group & 0.006 & 12 & 0.001 & & & \\
Total & 1.239 & 17 & & & & \\
\hline
\end{tabular}

Table 11. LSD multiple comparison of effect on extraction time of total flavonoids from Swordflower.

\begin{tabular}{llll}
\hline $\begin{array}{l}\text { Extraction } \\
\text { time (min) }\end{array}$ & $\begin{array}{l}\text { Average total flavonoids } \\
\text { content }(\mathbf{m g} / \mathbf{g})\end{array}$ & \multicolumn{2}{c}{ Significant differences } \\
\cline { 3 - 4 } & 6.806 & $\mathrm{a}=\mathbf{0 . 0 5}$ & $\mathbf{a}=\mathbf{0 . 0 1}$ \\
\hline 90 & 6.797 & $\mathrm{a}$ & $\mathrm{A}$ \\
60 & 6.760 & $\mathrm{a}$ & $\mathrm{A}$ \\
45 & 6.727 & $\mathrm{a}$ & $\mathrm{A}$ \\
30 & 6.560 & $\mathrm{a}$ & $\mathrm{AB}$ \\
15 & 6.063 & $\mathrm{~b}$ & $\mathrm{~B}$ \\
\hline
\end{tabular}

\subsubsection{Single Factor Test for Material Liquid Ratio}

The solid-liquid ratio was set to 1:10, 1:20, 1:30, 1:40, 1:50, 1:60, 1:70, 1:80 and 1:90 under the same fixed conditions as normal temperature, $90 \%$ ethanol and 30 minutes of extraction. The results were shown in Figure 5. Initially, the content of total flavonoids increased significantly with the decrease of feed-liquid ratio until the peak value was reached at 1:50, and the yield of total flavonoids reached $7.860 \mathrm{mg} / \mathrm{g}$. Subsequently, the amount of extraction decreased slowly.

The results of variance analysis (Table 12) showed that $\mathrm{F}>$ Fcrit and $\mathrm{P}<0.01$ showed that the ratio of material to liquid had a significant effect on the extraction of total flavonoids from Sagittaria septempunctata. By establishing multiple comparative analysis (Table 13), it was found that the extraction of total flavonoids from Sagittaria septempunctata reached a peak value at the ratio of material to liquid of 1:50, but reached a peak value of 1:40. There is no significant difference between 1:60, 1:70 and 1:80.

Based on the above analysis, in order to save the production cost on the basis of improving the total flavonoid extraction quantity, the optimum material-liquid ratio for the extraction of total flavonoids from Heptastar Swordflower was determined to be 1:50.

Table 12. Variance effect of material-liquid ratio on total flavonoids from Swordflower.

\begin{tabular}{llllll}
\hline Source of difference & SS & df & MS & F & P-value \\
\hline Inter group & 14.462 & 8 & 1.808 & $279.299 * *$ & 2.510 \\
Group & 0.117 & 18 & 0.006 & & $<0.001$ \\
Total & 14.578 & 26 & & \\
\hline
\end{tabular}

Table 13. LSD multiple comparison of material-liquid ratio on extraction of total flavonoids from Swordflower

\begin{tabular}{llll}
\hline $\begin{array}{l}\text { Material-liqui } \\
\text { d Ratio }(\mathbf{g} / \mathbf{m l})\end{array}$ & $\begin{array}{l}\text { Average content of total } \\
\text { flavonoids }(\mathbf{m g} / \mathbf{g})\end{array}$ & \multicolumn{2}{c}{ Significant difference } \\
\cline { 3 - 4 } $\mathbf{1 : 5 0}$ & 7.860 & $\mathrm{a}=\mathbf{0 . 0 5}$ & $\mathbf{a}=\mathbf{0 . 0 1}$ \\
$1: 60$ & 7.838 & $\mathrm{a}$ & $\mathrm{A}$ \\
$1: 70$ & 7.449 & $\mathrm{ab}$ & $\mathrm{A}$ \\
$1: 40$ & 7.446 & $\mathrm{ab}$ & $\mathrm{A}$ \\
$1: 80$ & 7.330 & $\mathrm{ab}$ & $\mathrm{A}$ \\
$1: 90$ & 7.223 & $\mathrm{~b}$ & $\mathrm{~A}$ \\
$1: 30$ & 7.062 & $\mathrm{~b}$ & $\mathrm{~A}$ \\
$1: 20$ & 5.860 & $\mathrm{c}$ & $\mathrm{B}$ \\
$1: 10$ & 5.740 & $\mathrm{c}$ & $\mathrm{B}$ \\
\hline
\end{tabular}

\subsubsection{Single Factor Test of Extraction Temperature}

Under the fixed conditions of $90 \%$ ethanol, 1:4 ratio of material to liquid, once extraction and 30 min extraction time, the temperature was $30 \%, 40 \%, 50 \%, 60 \%, 70 \%, 80 \%, 90 \%$, respectively. As shown in Figure 6, with the increase of extraction temperature, the content of total flavonoids increased first and then decreased gradually, reaching a peak at $70 \mathrm{C}$, when the extraction rate of total flavonoids was $6.637 \mathrm{mg} / \mathrm{g}$.

Through the analysis of variance (Table 14) and multiple comparisons (Table 15), we can see that $\mathrm{F}=210.774>$ Fcrit, and $\mathrm{P}<0.01$, indicating that the effect of different temperatures is very significant. The results showed that there was a significant difference between the extraction temperature of 70 ("peak level") and other levels. Therefore, the best temperature for extracting total flavonoids from sword flower was determined at $70 \mathrm{C}$.

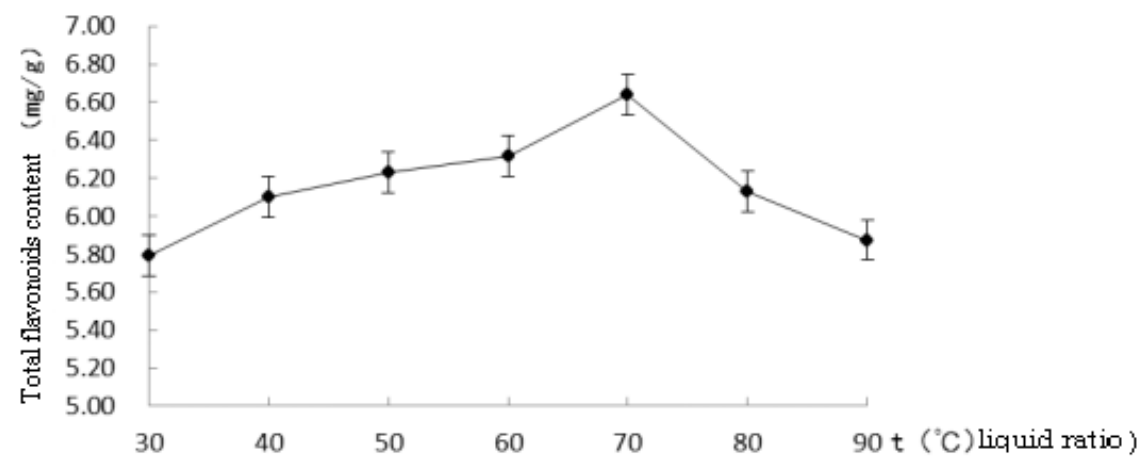

Figure 6. Effect of temperature on extraction of total flavonoids from sword flower. 
Table 14. Analysis of variance of effect of temperature of extraction on total flavonoids from Swordflower.

\begin{tabular}{lllllll}
\hline Source of difference & SS & df & MS & F & P-value & F crit \\
\hline Inter group & 1.435 & 6 & 0.239 & $210.774^{* *}$ & $<0.001$ & 2.848 \\
Group & 0.016 & 14 & 0.001 & & & \\
Total & 1.451 & 20 & & & & \\
\hline
\end{tabular}

Table 15. LSD multiple comparison of temperature of extraction on total flavonoids from Swordflower.

\begin{tabular}{llll}
\hline \multirow{2}{*}{$\mathbf{T}\left({ }^{\circ} \mathbf{C}\right)$} & $\begin{array}{l}\text { Average content of total } \\
\text { flavonoids }(\mathbf{m g} / \mathbf{g})\end{array}$ & \multicolumn{2}{c}{ Significant difference } \\
\cline { 3 - 4 } & 6.637 & $\mathbf{a}=\mathbf{0 . 0 5}$ & $\mathbf{a}=\mathbf{0 . 0 1}$ \\
\hline 70 & 6.315 & $\mathrm{a}$ & $\mathrm{A}$ \\
60 & 6.231 & $\mathrm{~b}$ & $\mathrm{~B}$ \\
50 & 6.132 & $\mathrm{~b}$ & $\mathrm{~B}$ \\
80 & 6.100 & $\mathrm{~b}$ & $\mathrm{BC}$ \\
40 & 5.875 & $\mathrm{~b}$ & $\mathrm{BC}$ \\
90 & 5.790 & $\mathrm{c}$ & $\mathrm{C}$ \\
30 & & $\mathrm{c}$ & $\mathrm{C}$ \\
\hline
\end{tabular}

\subsubsection{Orthogonal Test}

Table 16. Orthogonal test design and results.

\begin{tabular}{llllll}
\hline $\begin{array}{l}\text { Test } \\
\text { num }\end{array}$ & A & B & C & D & $\begin{array}{l}\text { Total flavonoids } \\
\text { (mg/g) }\end{array}$ \\
\hline 1 & 1 & 1 & 1 & 1 & $8.097 \pm 0.032$ \\
2 & 1 & 2 & 2 & 2 & $8.704 \pm 0.040$ \\
3 & 1 & 3 & 3 & 3 & $8.039 \pm 0.016$ \\
4 & 2 & 1 & 2 & 3 & $10.407 \pm 0.088$ \\
5 & 2 & 2 & 3 & 1 & $11.475 \pm 0.013$ \\
6 & 2 & 3 & 1 & 2 & $11.562 \pm 0.056$ \\
7 & 3 & 1 & 3 & 2 & $12.562 \pm 0.028$ \\
8 & 3 & 2 & 1 & 1 & $12.304 \pm 0.046$ \\
9 & 3 & 3 & 2 & 3 & $13.455 \pm 0.048$ \\
$\mathrm{k} 1$ & 24.840 & 31.065 & 32.044 & 31.876 & \\
$\mathrm{k} 2$ & 33.525 & 32.483 & 32.565 & 32.909 & \\
$\mathrm{k} 3$ & 38.320 & 33.137 & 32.076 & 31.900 & \\
$\mathrm{R}$ & 13.480 & 2.072 & 0.522 & 1.033 & \\
\hline
\end{tabular}

Based on the single factor tests, the ethanol concentration (A), solid-liquid ratio (B), extraction time (C) and extraction temperature (D) were taken as the factors to be investigated. The optimum levels of each factor were 90\%, 1:50, $45 \mathrm{~min}$ and $70^{\circ} \mathrm{C}$, respectively. Two treatment levels were selected near the optimal level to establish an orthogonal experiment of four factors and three levels (see Table 2), and to explore the optimal extraction process of total flavonoids from Heptastar Sword Flower. The experimental results are as follows. In Table 16, R value R1 $>\mathrm{R} 2>\mathrm{R} 4>\mathrm{R} 3$ can be judged as follows: $\mathrm{A}>\mathrm{B}>\mathrm{D}>\mathrm{C}$, i.e. ethanol concentration $>$ material-liquid ratio $>$ temperature $>$ extraction time. From the sum of the experimental factors $\mathrm{K}$, it can be seen that the combination of the optimal scheme is A3B3C2D2, namely: ethanol concentration 95\%, material-liquid ratio 1:60, extraction time $60 \mathrm{~min}$, extraction temperature $70^{\circ} \mathrm{C}$.

\subsubsection{Confirmatory Test}

The optimized condition on factors of A3B3C2D2 was used for three parallel extractions. The results showed that RSD was $1.464 \%$, indicating that the experiment had good reproducibility. After calculation, the average total flavonoids content was $13.41 \mathrm{mg} / \mathrm{g}$, reaching the maximum extraction amount in the orthogonal experiment.

\subsection{Identification of Flavonoids}

(1) Reaction of concentrated ammonia water: Using the volatility of concentrated ammonia water, spot B is fumigated on concentrated ammonia water in the fume hood, and then observed immediately in the sunlight. It could be observed that the color of spot B was obviously darker than that of spot A. This is a typical reaction to identify flavonoids. (see Figure 7).

(2) TLC: After the dot pattern and development are completed, the samples was observed under ultraviolet lamp. Compared with standard rutin solution, there was the same yellow fluorescent regions in the middle and lower parts of the same position. The other substances of several color spots need to be determined. It was preliminarily proved that the extract contains rutin (see Figure 8).

After ethanol extraction and ethyl acetate extraction, the above two methods of validating flavonoids were used to preliminarily prove that the second extract also contained flavonoids.

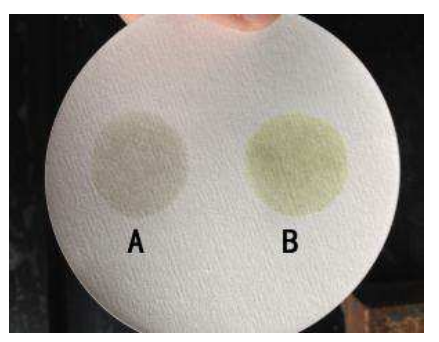

Figure 7. Speckle pattern of strong ammonia reaction.

Note: lamp Fumigation reaction of $\mathrm{A}$ and $\mathrm{B}$ in concentrated solution of ammonia. Left $\mathrm{A}$ is rutin standard, right $\mathrm{B}$ is sample liquid.

In the $\mathrm{AlCl}_{3}$ reaction test, yellow-green fluorescence was observed in the sample solution under the ultraviolet projector, which was consistent with the rutin standard (Figure 2), indicating that the solution contained flavonoids and flavonols.

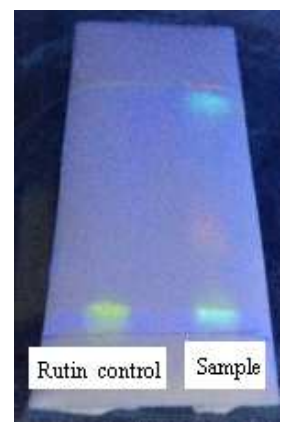

Figure 8. Thin layer chromatography results of ethanol extract of sword flower.

Note: Lamp Fumigation reaction of $\mathrm{A}$ and $\mathrm{B}$ in concentrated solution of ammonia 


\subsection{Determination of Flavonoid Content}

According to many preliminary experiments, the concentration of extract A and B was diluted four times and adjusted to $0.625 \mathrm{mg} / \mathrm{ml}$. The spectrophotometer was used to measure the spectrophotometry. The spectrophotometric values were brought into the formula $\mathrm{y}=10.765 \mathrm{x}-0.0138$, $\mathrm{R} 2=0.9562$, and the formula $\mathrm{W}(\mathrm{mg} / \mathrm{g})=(\mathrm{CxV} 1 \mathrm{xV} 2) / \mathrm{MxV} 3$ for total flavonoids, in which $\mathrm{C}(\mathrm{xV} 1 \mathrm{xV} 2) / \mathrm{MxV} 3$ was the best For the concentration of total flavonoid extract $(\mathrm{mg} / \mathrm{ml}), \mathrm{V} 1$ is the volume of solution to be measured $(14 \mathrm{ml})$, V2 is the total volume of extract $/ \mathrm{ml}, \mathrm{V} 3$ is the volume $/ \mathrm{ml}$ of extract to be measured, and $\mathrm{M}$ is the mass $/ \mathrm{g}$ of Sword Flower (see Table 17).

Compared with the total flavonoids extracted before and after ethyl acetate extraction, the total flavonoids extracted after extraction is more than twice as much as before extraction. The extraction of flavonoids was greatly improved than ethanol extraction.

Table 17. Fraction and total flavonoid extraction amount

\begin{tabular}{lll}
\hline $\begin{array}{l}\text { Extracted } \\
\text { fluid }\end{array}$ & Fractionation & Total flavonoids extraction $(\mathbf{m g} / \mathbf{g})$ \\
\hline A & 0.289 & 3.94 \\
B & 0.797 & 10.54 \\
\hline
\end{tabular}

\subsection{Inhibition of Rutin and Two Extracts on Different Bacteria}

The results of bacteriostasis experiment showed that the extract of Sword Flower had certain inhibitory effects on Escherichia coli, Bacillus subtilis and Staphylococcus aureus. When the concentration was $10 \mathrm{mg} / \mathrm{ml}$, the maximum inhibitory zones were $11.27 \mathrm{~mm}, 10.13 \mathrm{~mm}$ and $10.83 \mathrm{~mm}$ respectively, while the maximum inhibitory zones of rutin were $11.5 \mathrm{~mm}$, $10.23 \mathrm{~mm}$ and $8.8 \mathrm{~mm}$ respectively. Overall, the antibacterial effect of extracts from the flower of sword flower on E. coli and Bacillus subtilis is better than rutin. The data were statistically significant $(\mathrm{P}<0.05$, see Table 18 and table 19$)$.
Table 18. Bacteriostatic circle size of rutin solution with different concentrations to the bacteria.

\begin{tabular}{llll}
\hline \multicolumn{2}{l}{ Rutin inhibition zone (mm) } & & \\
\hline & $\begin{array}{l}\text { Escherichia } \\
\text { coli }\end{array}$ & Bacillus subtilis & $\begin{array}{l}\text { Staphylococcus } \\
\text { aureus }\end{array}$ \\
\hline $95 \% \mathrm{Ethanol}$ & $7.83 \pm 0.04$ & $8.23 \pm 0.06$ & $7.47 \pm 0.44$ \\
$10 \mathrm{mg} / \mathrm{ml}$ & $11.5 \pm 0.61$ & $10.23 \pm 0.20$ & $8.8 \pm 0.19$ \\
$5 \mathrm{mg} / \mathrm{ml}$ & $11.1 \pm 0.35$ & $9.97 \pm 0.20$ & $8.2 \pm 0.19$ \\
$2.5 \mathrm{mg} / \mathrm{ml}$ & $10.63 \pm 0.11$ & $9.57 \pm 0.11$ & $8.07 \pm 0.78$ \\
$1.25 \mathrm{mg} / \mathrm{ml}$ & $10.23 \pm 0.31$ & $9.13 \pm 0.55$ & $7.9 \pm 0.25$ \\
$0.625 \mathrm{mg} / \mathrm{ml}$ & $9.8 \pm 0.45$ & $8.83 \pm 0.03$ & $7.63 \pm 0.02$ \\
\hline
\end{tabular}

Table 19. Bacteriostatic circle size of extract solution with different bacteria concentrations.

\begin{tabular}{llll}
\hline \multicolumn{3}{c}{ Bacteriostasis circle of extract B $(\mathbf{m m})$} & \\
\hline & $\begin{array}{l}\text { Escherichia } \\
\text { coli }\end{array}$ & Bacillus subtilis & $\begin{array}{l}\text { Staphylococcus } \\
\text { aureus }\end{array}$ \\
\hline $95 \% \mathrm{Ethanol}$ & $7.83 \pm 0.04$ & $8.23 \pm 0.06$ & $7.47 \pm 0.44$ \\
$10 \mathrm{mg} / \mathrm{ml}$ & $11.27 \pm 0.63$ & $10.13 \pm 0.38$ & $10.83 \pm 0.06$ \\
$5 \mathrm{mg} / \mathrm{ml}$ & $10.73 \pm 0.11$ & $10.00 \pm 1.14$ & $9.6 \pm 0.33$ \\
$2.5 \mathrm{mg} / \mathrm{ml}$ & $9.9 \pm 0.74$ & $9.83 \pm 0.44$ & $9.23 \pm 0.44$ \\
$1.25 \mathrm{mg} / \mathrm{ml}$ & $9 \pm 0.42$ & $9.73 \pm 0.43$ & $8.93 \pm 0.81$ \\
$0.625 \mathrm{mg} / \mathrm{ml}$ & $8.8 \pm 1.33$ & $9.5 \pm 1.26$ & $8.63 \pm 0.04$ \\
\hline
\end{tabular}

\subsection{Scavenging Effect of Rutin and Two Extracts on Hydroxyl Radical}

Experiments show that the extract of Sword Flower has a certain scavenging effect on hydroxyl free radicals, and with the increase of concentration, the scavenging rate of hydroxyl free radicals also increases. Compared with rutin as the control group, the scavenging effect of the two extracts on hydroxyl radicals were similar. The scavenging effect of the extracts from Sword Flower was more obvious at lower concentration than that of rutin, while the scavenging effect of the extracts from Sword Flower was slightly lower at higher concentration than that of rutin. The data were statistically analyzed, with significant difference $(\mathrm{P}<0.05$, see Table 20 and Figure 9).

Table 20. Analysis of hydroxyl radical scavenging of flavonoid extracts from Swordflower.

\begin{tabular}{lllll}
\hline Flavonoid content (mg) & 0.4 & 0.5 & 0.6 & 0.7 \\
Rutin removal rate (\%) & $25.5 \pm 1.72$ & $41.4 \pm 12.79$ & $65.2 \pm 0.79$ & $78.7 \pm 0.48$ \\
Removal rate of extractive solution (\%) & $36.7 \pm 29.8$ & $51.4 \pm 1.09$ & $63.1 \pm 4.44$ & $72.9 \pm 0.91$ \\
\hline
\end{tabular}

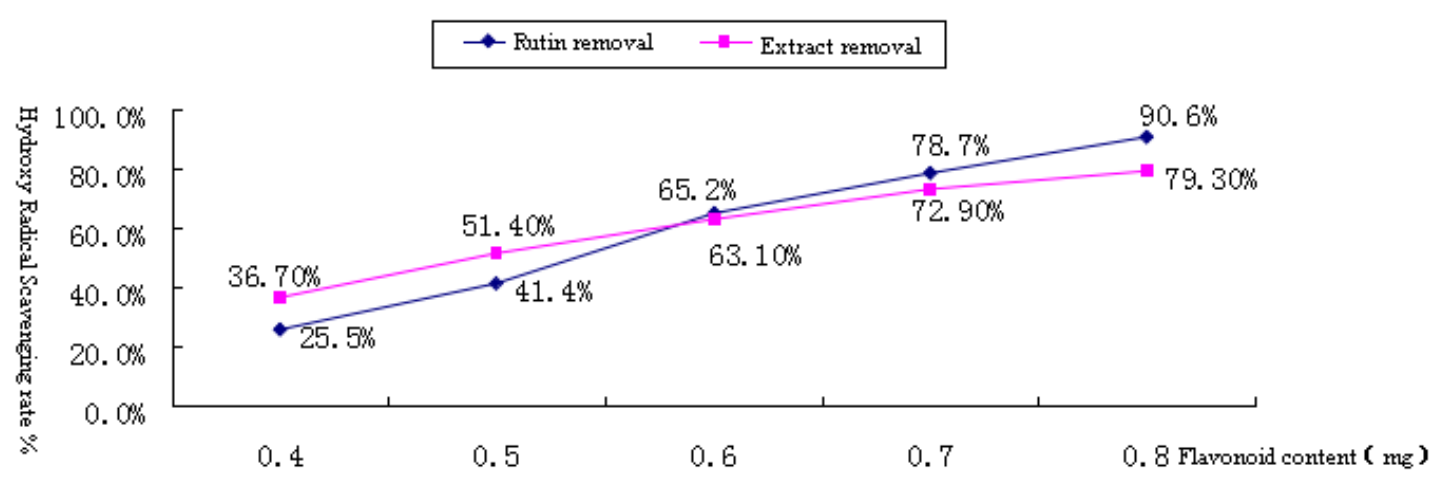

Figure 9. Effects of rutin and sample solution on hydroxyl radical scavenging. 


\section{Discussion}

Sword flower is a plant of the genus Dipsacus in Cactaceae. Zhaoqing is one of the main production areas of Jianhua in China. It is sold well in domestic and foreign markets. mainly used for food, soup and drink. In particular, it can clear away heat and moisten lung, stop cough and phlegm, and be used to treat hot phlegm cough, tuberculosis, scrofula, bronchitis and other diseases [1-4]. It can also strengthen the body and nourish the health [14-16]. According to Yi Yan et al. [7], 13 kinds of flavonoids in Jianhua were separated and purified, but the raw material was from Guangzhou City [17], and the report was limited to the qualitative analysis of flavonoids in xiphophora. In addition, there are no reports on the ultrasonic and alcohol extraction of Flavonoids from swordfish. It can be seen that this experiment has some innovation.

There are many methods to extract flavonoids, such as water extraction, ultrasonic extraction, supercritical fluid extraction and so on. Most of the effective components of natural plants, such as alkaloids, polysaccharides, flavonoids and other compounds, are intracellular products. It is more conducive to the extraction of substances when the plant cells are broken. However, the commonly used mechanical breaking method can not make the cell break efficiently because of the barrier effect of the cell membrane, and the chemical breaking method will lead to the change of the structure or chemical properties of the extract and lead to its deactivation, so it is difficult to achieve the ideal extraction effect by these methods. In the new era of science and technology, ultrasonic extraction method solves the problems brought by these methods very well. The existing mechanical crushing method combined with ultrasonic is applied to plant extraction, which is convenient and fast in operation, high in extraction rate, short in time, complete in structure and good in extraction effect, showing obvious advantages. It is reported that flavonoids are contained in the extract of Jianhua [17].

In this experiment, 90-95\% ethanol and ultrasonic treatment were used to extract the total flavonoids from sword flower, and the amount of flavonoids extracted was $3.94 \mathrm{mg} / \mathrm{g}$; while Li Yingchang et al. Soaked blueberry leaves in 70\% ethanol to extract the total flavonoids, the extraction rate was $0.695 \mathrm{mg} / \mathrm{g}$ [18], the amount of flavonoids extracted by this method was more than 5 times higher than Li Yingchang et al [4]. In addition to the difference in methods, it may also be caused by the difference in flavonoids content between blueberry leaves and swordfish.

In plants, the antibacterial effect of different parts is different, because different positions have different active ingredients. The contact probability of the pathogen and the flower with insect as the infection carrier is high, so the flower of the plant has a good defense mechanism and a high antibacterial activity [7]. The experimental material of this study is Qixing jianhua, which is the organ of the plant flower. Theoretically, it should have antibacterial activity. The results showed that the inhibition of Staphylococcus aureus, Bacillus subtilis and Escherichia coli were the same as that of rutin, and the inhibition circle was as follows: Escherichia coli $>$ Bacillus subtilis > Staphylococcus aureus. From the perspective of the size of the bacteriostatic circle, it was found that the bacteriostatic effect of the second extract on $E$. coli was slightly lower than that of rutin, but the bacteriostatic circle of Staphylococcus aureus was significantly larger than that of rutin. The bacteriostatic effect of the two extracts on Bacillus subtilis was similar, but in general, swordfish extract was dominant, probably because there were some bacteriostatic substances other than flavonoids in the extract, resulting in The inhibition zone of Staphylococcus aureus and Bacillus subtilis is larger than rutin, which need to be studied. Li Bengjie et al [8]. Used alcohol extraction method to extract substances only to inhibit Bacillus subtilis, acetone extraction method only to inhibit Staphylococcus aureus, and ethyl acetate extract has the best antibacterial effect, but no inhibitory effect on Bacillus subtilis, and the antibacterial effect on the other two kinds of bacteria are better than this experiment, the reasons may be: (1) using different dissolving The substances extracted from quality are different, so they have different bacteriostatic effects on different strains. (2) The higher the concentration of the extract, the larger the bacteriostatic circle. (3) Operation method, etc. All in all, through the filter paper bacteriostatic test plate method, it is proved that the extract of sword flower has bacteriostatic effect, and the bacteriostatic effect for Staphylococcus aureus is better than rutin solution, which provides a theoretical basis for the application of sword flower flavonoids in medicine.

Jianhua, as a special product of Zhaoqing, is rich in nutrients and mineral elements. It has been proved that Jianhua has antibacterial and antioxidant effects. If this will be developed into a new hot - selling food, such as Jianhua compound beverage [18], as a healthy health drink, it can increase people's awareness of Jianhua. Nowadays, many antiseptic and antibacterial agents are compound synthesis, which is harmful to our health. Therefore, natural antiseptic and antibacterial agents are of great significance to the antiseptic preservation of food. The results of the bacteriostatic effect of Jianhua can well prove that Jianhua has a great development prospect as a natural antiseptic and antibacterial agent. Hydroxyl radicals can kill red blood cells, degrade DNA, cell membrane and polysaccharide compounds, which have serious harm to our human body. However, swordfish has a good effect of scavenging hydroxyl radicals, which can help us to scavenge hydroxyl radicals in our body.

At least, 13 flavonols and their glycosides have been isolated and identified by Yi Yan, Wu Xin, Wang Ying et al [17]. There are many extraction technologies for flavonoids, such as alcohol extraction, alkali extraction, enzyme assisted extraction, microwave extraction, supercritical extraction technology, etc. each extraction method has its own advantages and disadvantages. The selection of extraction methods depends on the comprehensive experimental materials and equipment. The traditional ethanol extraction method is adopted in this paper, which has the advantages of low production cost, simple operation and easy control of 
technological conditions.

At present, there is no relevant report on the content and extraction technology of total flavonoids in the flower, especially on the extraction technology of the flower. In this experiment, seven star sword flower, a genuine medicinal plant in Zhaoqing, was used as raw material, and two different processes, extraction method and ultrasonic method, were used for comparative test to optimize the drug extraction process. Through a series of single factor tests and the analysis of variance of the results of each single factor test, it is found that the factors such as ethanol concentration, the size of Jianhua granules, and the number of times of extraction have significant influence on the yield of total flavonoids of Jianhua within the scope of investigation. On this basis, the orthogonal experiment of L9 (3 squere 4) was carried out with four factors of ethanol concentration, material liquid ratio, extraction time and temperature, so as to optimize the extraction process of total flavonoids from seven star sword flower. The results showed that the influence degree of each factor was ethanol concentration $>$ material liquid ratio $>$ extraction temperature $>$ extraction time, in which ethanol concentration was the main factor affecting the extraction of total flavonoids. In this study, the extracted flavonoids were also identified, including aluminum chloride reaction and thin plate chromatography as references above mentioned.

Free radical is a kind of substance that must be produced in life. If excessive active free radical is produced, it will cause damage to the body, especially hydroxyl radical [19]. Hydroxyl radicals have a strong effect on lipid peroxidation. Its peroxidation is not only the main cause of membrane lipid peroxidation, but also an important factor that can not be ignored to cause DNA damage [20]. The results showed that rutin, a flavonoid control substance, and the flavone extract of swordfish had scavenging effects on hydroxyl radicals, and the antioxidant effect increased with the increase of flavone content. In the concentration range, the scavenging rate of the extract to hydroxyl radicals was $79.3 \%$, and that of rutin was $90.6 \%$, which was not different from that of rutin. In Duan Zhifang et al [1]. Water extraction of sword flower (main components are total sugar, total tannin, total amino acid, total calculation and total saponin) has scavenging effect on hydroxyl radicals [1]. Compared with this experiment, it is found that the scavenging rate of swordfish extract (main extract is flavone) in this experiment is much higher than that in Duan Zhifang et al. Which is the largest The reason is that different substances are extracted, so the scavenging effect of hydroxyl radicals is also different.

This study is of theoretical and practical significance for the future study on the technology of Extracting Flavonoids from plants and the utilization of flavonoids in Zhaoqing genuine medicine Jianhua.

In this study, we explored the extraction and separation technology of the flavonoid and the analysis of its properties. Because of its antioxidant and bacteriostatic properties, it is assumed that it can be used for antiviral research. This is because many studies have shown that the active ingredients extracted from traditional Chinese medicines have immune and antiviral properties [21]. If the research results can be used in the future anti-virus, Sword flower from Zhaoqing will be the first use of genuine drugs.

\section{Conclusion}

This study is of theoretical and practical significance for the future study on the technology of Extracting Flavonoids from plants and the utilization of flavonoids in Zhaoqing genuine medicine Jianhua. In this study, we explored the extraction and separation technology of the flavonoid and the analysis of its properties. Because of its antioxidant and bacteriostatic properties, it is assumed that it can be used for antiviral research. This is because many studies have shown that the active ingredients extracted from traditional Chinese medicines have immune and antiviral properties. If the research results can be used in the future anti-virus, Sword flower from Zhaoqing will be the first use of genuine drugs.

\section{References}

[1] Duan zhifang, Fu li. Study on free radical scavenging effect of liquified components extracted from sword flower water, Food science and technology, 2011, 36 (9): 262-265.

[2] Shao ling, Zhu qiao, Chen yan-fang, Zeng chun-yu, Ding jun-wei, Yang xue-wen. Study on the extraction of polysaccharide from polygonum multiflorum and evaluation of DPPH free radical scavenging capacity $[\mathrm{J}]$. Guangdong agricultural sciences, 2014, 41 (17): 101-05.

[3] Liu peng, lai shuying, huang aidong. Determination and analysis of microelements and constants in jianhua [J]. Science of microelements in guangdong, 1997, 4 (9): 65-6.

[4] Li yingchang, Lv yanfang. Extraction and qualitative analysis of total flavonoids from blueberry leaves [J]. Food and fermentation technology, 2012, 48 (4) 32-36.

[5] Fan Chenglang, Wang xuesong, Zang wei, Li hui, Sun jianqiu.. Color reaction and application of paclitaxel by TLC [J]. China brewing, 2012, 31 (9): 160161.

[6] Chen x e, Fang x b, Yu h, Liao z. TLC analysis of chitosan oligosaccharides [J]. Journal of zhejiang ocean university (natural science edition), 2008, 27 (4): 36-365.

[7] Yi yan Wu xin, Wang ying, Ye wencai, Zhang qingwen, Ba wang. A study on the flavonoids of flowers "Chinese herbal medicine", May 2011, 712-716.

[8] Li bing-jie, Huang mao-chun, Liao yanfang, Chen rui, Lv jinyan. Study on antioxidant and antimicrobial activity of the extract of bong flower [J]. Food industry science and technology, 2014, 07 (35): 80-86.

[9] Xu ying-shu, Long yan-yu. Determination of flavonoids in ethyl acetate extract from hueergrass by ultraviolet spectrophotometry [J]. Journal of zunyi medical college, 2011, 34 (3): 298-300.

[10] Zhan suqiong, Yuan dingsheng, Li xuding, Li jinliang, Yin zhongqiong. Qualitative analysis and determination of total flavones in ranunculus chinensis [J]. Journal of anhui agricultural sciences. 2010, 38 (28): 15580-15582. 
[11] Yan jun, Gou xiao-jun, zou quanfu, Ji xiaoming, Cui xiuying, Lan hairong, Li xue. Spectrophotometric determination of hydroxyl radicals produced by Fenton reaction [J]. Journal of chengdu university (natural science, 2009, 28 (2): 91-93.

[12] Wen jing, He suhua, Zhang Bo cheng, Yang jianfeng, Chang ping, Guo yu. In vitro experimental study on the scavenging of $\mathrm{O}_{2}-\bullet$ and $\bullet \mathrm{OH}$ by rhodiola rosea extract $[\mathrm{J}]$. Food science 2005 , 26 (2): 219-223.

[13] Yue jin, Yang guiyun, Deng yun, Qian bingjun, Wang danfeng, Zhao yanyun. Antimicrobial effect of plant extract and its application in food [J]. Journal of agricultural science, Shanghai jiao tong university, 2013, 31 (5): 36-53.

[14] Yan xi, Liu huiqing, Zou yongqing, Ren zhanhua. Advances in the physiological activities and synthesis of flavonoids [J] organic chemistry, 2008, 28 (9): 1534-1544.

[15] Fu shujie, Huang xingzhen, Wu lingling, Long fengming, Wei xiuzhi, Jiang weizhe. Study on the antitussive, expectorant and antiasthmatic effects of extracts from sword flower [J]. Journal of drug evaluation and research, 2013, 36 (1): 18-21.
[16] Zhu h, Gao r, Wang d w, Wang $r$ q. Advances in the study of ginkgo flavones [J]. Food and medicine, 2005, 7 (2A): 4-7.

[17] Song li-ren, hong xun, ding xu-liang, zang za-yang. Dictionary of modern Chinese materia medica (part 1 and part 2) [M]. Beijing: people's medical publishing house, 2001: 156.

[18] Zhang yan, xu yujuan, li yan. Development of jianhua compound drink [J]. Technology \& food engineering, 2009, 34 (1): 126-127.

[19] Wen jing, zhang xi, chang ping. Evaluation of antioxidant function of health food by detection of hydroxyl free radical content in mice [J]. Food science, 2008, 29 (1): 286-291.

[20] Li chengliang, Chen yusuo, Li liangjun, Zhang fengmin, Qi bin, Qian jianya. Extraction and antioxidant properties of flavonoids from Gordon uryale seed [J]. Yangtze river vegetables (science edition), 2010, 40 (14): 57-61.

[21] Yan Min, Tang Xiaolu. A survey of the research on the antiviral effect of flavonoid. Asia pasific traditional medicine 2009, Vol. 5 no. 9 149-150. 